\title{
Differential expression of secreted frizzled-related protein 4 in decidual cells during pregnancy
}

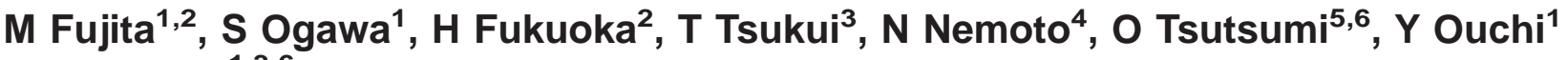 \\ and $\mathbf{S}$ Inoue $\mathbf{e}^{1,3,6}$ \\ ${ }^{1}$ Department of Geriatric Medicine, Graduate School of Medicine, University of Tokyo, 7-3-1, Hongo, Bunkyo-ku, Tokyo 113-8655, Japan \\ ${ }^{2}$ Department of Developmental Medical Sciences, Institute of International Health, Graduate School of Medicine, University of Tokyo, 7-3-1, Hongo, \\ Bunkyo-ku, Tokyo 113-0033, Japan \\ ${ }^{3}$ Department of Biochemistry and Research Center for Genomic Medicine, Saitama Medical School, Morohongo, Moroyama-machi, Iruma-gun, \\ Saitama 350-0495, Japan \\ ${ }^{4}$ Department of Pathology, School of Medicine, Nihon University, 30-1, Oyaguchikami-machi, Itabashi-ku, Tokyo 173-8610, Japan \\ ${ }^{5}$ Department of Obstetrics and Gynecology, Faculty of Medicine, University of Tokyo, 7-3-1, Hongo, Bunkyo-ku, Tokyo 113-8655, Japan \\ ${ }^{6}$ CREST, Japan Science and Technology Corporation, Kawaguchi, Saitama 332-0012, Japan
}

(Requests for offprints should be addressed to S Inoue; Email: inoworld-tky@umin.ac.jp)

\begin{abstract}
During pregnancy, the uterus shows marked morphological and physiological changes under the regulation of ovarian steroid. To elucidate the molecular cues of these changes, we tried to identify the transcripts differentially expressed in the pregnant rat uterus by using the suppression subtractive hybridization method. Seven independent clones were isolated and one of the up-regulated genes was secreted frizzled-related protein 4 (sFRP4). sFRP4 contains a Wnt-binding domain and belongs to the secreted frizzled protein family whose members are assumed to function as modulators of the Wnt signal. The expression level of sFRP4 mRNA reached a peak in the pregnant uterus on day 12, when uterine decidualization was almost complete in the rat. In situ hybridization histochemistry revealed that sFRP4 transcripts were observed in the decidual cells. In addition, proliferating cell nuclear antigen (PCNA)-positive cells were shown to be overlapped in decidua, suggesting that sFRP4 mRNA expression was accompanied by the late phase of decidual cell proliferation. Moreover, sFRP4 and estrogen receptor- $\alpha$ transcripts were co-localized. Furthermore, we analyzed the regulation of SFRP4 by estrogen using 17ß-estradiol-treated ovariectomized rats. sFRP4 mRNA was detected in the uterus at $48 \mathrm{~h}$ after estrogen treatment, especially in endometrial stroma where PCNA-positive cells were also observed. The results in this study led us to the notion that SFRP4 mRNA may be up-regulated after estrogen treatment in the late phase of uterine cell proliferation.
\end{abstract}

Journal of Molecular Endocrinology (2002) 28, 213-223

\section{Introduction}

The uterus undergoes morphological and physiological changes during gestation to accommodate and protect the developing conceptus. Both estrogen and progesterone play important roles in this process, maintaining uterine quiescence during gestation and determining the onset of parturition (Fu et al. 1994, Chibbar et al. 1995, Hansen 1998, de Ziegler et al. 1998). To elucidate the molecular basis of these mechanisms, it is important to identify the genes and factors involved in the pregnant uterus. For example, the expression of collagen type I and III and fibronectin is increased in the myometrium of the pregnant uterus (Stewart et al. 1995), suggesting their physiological roles in the growth of the uterus during pregnancy. Several cytokines are also expressed in the pregnant uterus (Lim et al. 1998, Hatthachote \& Gillespie 1999). Leukemia inhibitory factor, required for successful implantation, is secreted in the uterine endometrial gland (Charnock et al. 1994, Vogiagis \& Salamonsen 1999). Macrophage-colony stimulating factor is widely distributed in the endometrium, 
decidua and placenta, suggesting its role in placental morphogenesis and trophoblast differentiation (Saito et al. 1994). It is well recognized that regulation of these factors provides a framework for understanding gestational changes of the uterus. Especially, the up-regulated genes during implantation and parturition are investigated because they are important for establishment of pregnancy and the onset of labor. However, relatively few factors up-regulated during the mid and late phase of pregnancy have been identified so far. During the later phase of pregnancy, the decidualization is completed and then decidual cell regression occurs (Ogle et al. 1999). In addition, myometrium is undergoing hypertrophy (Macphee \& Lye 2000) accompanied by a significant increase of fetal mass (Dowell \& Kauer 1997). To investigate the up-regulated genes in this period is important for understanding the precise mechanism of these changes.

In the present study, we tried to isolate the genes regulated in the later phase of the pregnant rat uterus, including downstream targets regulated by ovarian hormone, by using suppression subtractive hybridization (SSH) (Diatchenko et al. 1996). Here, we identified a predominant expression of the secreted frizzled-related protein 4 (sFRP4), a member of the secreted frizzled family, whose expression gradually elevated until mid-pregnancy. The distribution of sFRP4 transcripts was also examined by in situ hybridization histochemistry. To explore the possible role of sFRP4 expression in cell proliferation, co-localization of sFRP4 mRNA with proliferating cell nuclear antigen (PGNA) (Kelman \& Hurwitz 1998, Tsurimoto 1998) in the uterus was analyzed. Then, we examined the hormonal regulation of sFRP4 expression in ovariectomized rats treated with $17 \beta$-estradiol.

\section{Materials and methods}

\section{Animals and tissue preparation}

Female 9-week-old Wistar rats with or without pregnancy were purchased from Charles River Japan (Tokyo, Japan). For pregnant rats, the day a vaginal plug was found was designated day 0 , and rats on days $6,9,12$ and 15 were used. The tissue preparation for Northern blot analysis was performed as follows. After surgical removal of the uteri under anesthesia, they were rapidly opened, and the pups and placenta were removed. The tissues were frozen in liquid nitrogen and stored at $-80{ }^{\circ} \mathrm{C}$ until RNA isolation. For in situ hybridization and immunohistochemistry, tissues were fixed with 4\% paraformaldehyde in PBS and embedded in paraffin. The serial sections were cut and mounted on slides and stored at $4{ }^{\circ} \mathrm{C}$. For estradiol treatment study, rats were ovariectomized. Two weeks after surgery, the rats received an s.c. injection of additional estradiol $(10 \mu \mathrm{g} / \mathrm{kg}$ body weight) (Sigma, St Louis, MO, USA) suspended in olive oil and then killed 0, 2, 6, 24 and $48 \mathrm{~h}$ later. All animal studies followed the National Institutes of Health (NIH) guidelines for the Care and Use of Experimental Animals.

\section{Total RNA and poly A+ RNA isolation}

Total RNA was extracted from frozen nonpregnant and pregnant uteri using Isogen reagent (Nippon Gene, Tokyo, Japan). Poly A+ RNA was extracted from $250 \mu \mathrm{g}$ total RNA using an Oligotex-dT30 mRNA purification kit (Takara Shuzo, Tokyo, Japan).

\section{SSH}

The subtraction cDNA library was made using a PGR-Select cDNA subtraction kit, according to the manufacturer's instruction (Clontech, Palo Alto, CA, USA). Briefly, poly A+ RNA obtained from day 15 pregnant uteri and non-pregnant uteri were designated as a tester and a driver respectively. The double-stranded cDNAs were synthesized from $2 \mu \mathrm{g}$ of each poly A+ RNA. The synthesized double-stranded cDNAs were then digested with RsaI and ligated to adapters. Subtractive hybridizations were performed between the tester and the driver and the hybridization products were amplified by PGR (Diatchenko et al. 1999).

\section{Sequences analysis}

The amplified cDNA fragments from the secondary PCR were ligated into a pCRII vector using a T/A cloning kit (Invitrogen, Madison, WI, USA). Fifty clones were isolated and sequenced by an ALF auto sequencer (Pharmacia Biotech, Tokyo, Japan) with an Autoreading sequencing kit (Pharmacia Biotech). The retrieved sequences were aligned with cDNA sequences in the GenBank 
nucleotide database at the National Center for Biotechnology Information (NIH, Bethesda, MD, USA) using the Blastn program to search for sequence matches (http://www.ncbi.nlm.nih.gov/ blast/).

\section{Northern blot analysis}

Total RNA was prepared from non-pregnant uteri and pregnant uteri on days 6, 9, 12 and 15 as described above. Total RNA (20 $\mu \mathrm{g} /$ lane $)$ was separated in 1\% agarose gel. Northern blot analysis was performed as described previously (Ogawa et al. 1998). The sFRP4 cDNA fragment obtained by SSH and the glyceraldehyde-3-phosphate dehydrogenase (GAPDH) cDNA fragment (Orimo et al. 1995) were labeled with $\left[\alpha-{ }^{32} \mathrm{P}\right] \mathrm{dCTP}$ using a BcaBEST Labeling kit (Takara Shuzo) and used as probes. Autoradiography was carried out at $-80{ }^{\circ} \mathrm{C}$ with an intensifying screen for $48 \mathrm{~h}$. The intensity of the hybridization band was measured using BioMax 1D image analysis software (Kodak, Rochester, NY, USA).

\section{In situ hybridization histochemistry}

Digoxigenin (DIG)-labeled single-stranded RNA probes were prepared using a DIG RNA labeling kit (Roche Diagnostics, Rotkreutz, Switzerland). The sFRP4 riboprobe was generated using a $474 \mathrm{bp}$ cDNA fragment obtained by SSH. The estrogen receptor- $\alpha(\mathrm{ER} \alpha)$ riboprobe was generated from a $1803 \mathrm{bp}$ full-length fragment containing the entire open reading frame of the receptor (Koike et al. 1987). In situ hybridization histochemistry was performed as described previously (Ishikawa et al. 1999). The sections were deparaffinized, rehydrated, incubated with $20 \mu \mathrm{g} / \mathrm{ml}$ proteinase $\mathrm{K}$ for $30 \mathrm{~min}$ at room temperature, treated with $0.2 \mathrm{M}$ $\mathrm{HCl}$ for $10 \mathrm{~min}$, and then acetylated. Hybridization was carried out at $55^{\circ} \mathrm{C}$ for $18 \mathrm{~h}$ in a solution containing $25 \%$ formamide, $1.25 \times \mathrm{SSC}, 0 \cdot 1 \%$ SDS, $50 \mu \mathrm{g} / \mathrm{ml}$ heparin, $50 \mu \mathrm{g} / \mathrm{ml}$ yeast RNA, and $1 \mu \mathrm{g} / \mathrm{ml}$ RNA probe. After washing twice with solution I (50\% formamide, $5 \times \mathrm{SSC}, 1 \% \mathrm{SDS})$ at $55{ }^{\circ} \mathrm{C}$ for $30 \mathrm{~min}$ and three times with solution II (0.5 M NaCl, $10 \mathrm{mM}$ Tris-HCl, $0 \cdot 1 \%$ Tween 20) at room temperature for $10 \mathrm{~min}$, the sections were treated with $25 \mu \mathrm{g} / \mathrm{ml}$ RNase A to remove non-specific binding of the probe. The sections were reacted with blocking solution containing casein (Roche Diagnostics) for $1 \mathrm{~h}$, and incubated with alkaline phosphatase-labeled anti-DIG antibody for $18 \mathrm{~h}$. The sections were washed and incubated with the chromogenic substrate solution containing 4-nitroblue tetrazolium chloride and 5-bromo-4-chloro-3-indolyl-phosphate (Roche Diagnostics) until adequate staining was observed.

\section{Immunohistochemistry}

PGNA was detected using immunohistochemical staining. After sections were hydrated, non-specific binding was blocked with PBS containing 10\% fetal bovine serum (FBS) for $1 \mathrm{~h}$. The sections were incubated with anti-PCNA mouse monoclonal antibody (Santa Cruz Biotechnology, Santa Cruz, CA, USA) or mouse IgG as a negative control diluted 1:500 in PBS containing 10\% FBS for $18 \mathrm{~h}$ at $4{ }^{\circ} \mathrm{C}$, followed by biotinylation with secondary antibody (anti-mouse rabbit immunoglobulins including $\operatorname{IgG}$, IgA and $\operatorname{IgM}$ ) for $1 \mathrm{~h}$ at room temperature. Sections were incubated with streptavidin conjugated with horseradish peroxidase and visualized by using peroxidase substrate 3,3'diaminobenzidine (Histofine SAB-PO kit, DAB substrate kit; Nichirei Inc., Tokyo, Japan).

\section{Results}

\section{Analysis of SSH PCR products}

We selected fifty cDNA clones from the $\mathrm{SSH}$ cDNA library constructed between pregnant uteri on day 15 and non-pregnant uteri. The sequences were analyzed for similarity against all nonredundant database sequences using the gapped BLAST search. The isolated genes were summarized in Table 1. Some of the isolated clones corresponded to expressed sequence tags (ESTs). Seven differentially expressed clones were isolated from 50 clones and six out of seven clones were previously known genes that up-regulate during pregnancy, namely; $\alpha-2$ macroglobulin (Fletcher et al. 1988, Thomas 1993), placental lactogen II (Faria et al. 1990), calcyclin (Thordarson et al. 1991, Waterhouse et al. 1992), plasma glutathione peroxidase (Takahashi et al. 1990), amiloridebinding protein (Lingueglia et al. 1993), and pregnancy-specific glycoprotein rnCGM (Chen et al. 1994). Interestingly, the last clone out of the 
Table 1 Up-regulated genes in pregnant rat uterus isolated by suppression subtractive hybridization (SSH)

\begin{tabular}{|c|c|c|c|c|c|}
\hline & cDNA & Localization & Day & Species & Reference \\
\hline Novel & sFRP4 & n.d. & n.d. & Rat & - \\
\hline \multirow[t]{6}{*}{ Known } & $\alpha-2$ Macroglobulin & $\begin{array}{l}\text { Decidua, } \\
\text { fetal liver }\end{array}$ & $6-21$ & Rat & $\begin{array}{l}\text { Fletcher et al. (1988) } \\
\text { Thomas (1993) }\end{array}$ \\
\hline & Placental lactogen II & $\begin{array}{l}\text { Decidua, } \\
\text { placenta, } \\
\text { trophoblast giant cell }\end{array}$ & $8-13$ & $\begin{array}{l}\text { Mouse, } \\
\text { rat }\end{array}$ & Faria et al. (1990) \\
\hline & Calcyclin & $\begin{array}{l}\text { Uterus, } \\
\text { decidua, } \\
\text { placenta }\end{array}$ & $5-18$ & Mouse & $\begin{array}{l}\text { Thordarson et al. (1991) } \\
\text { Waterhouse et al. (1992) }\end{array}$ \\
\hline & Plasma glutathione peroxidase & Placenta & n.d. & Human & Takahasshi et al. (1990) \\
\hline & Amiloride-binding protein & Placenta & n.d. & $\begin{array}{l}\text { Human, } \\
\text { rat }\end{array}$ & Lingueglia et al. (1993) \\
\hline & $\begin{array}{l}\text { Pregnancy specific glycoprotein } \\
\text { rnCGM3 }\end{array}$ & Placenta & n.d. & Rat & Chen et al. (1994) \\
\hline \multirow[t]{2}{*}{ EST } & EST 207450 (Al012999) & n.d. & n.d. & Rat & - \\
\hline & EST 212820 (Al103531) & n.d. & n.d. & Rat & - \\
\hline
\end{tabular}

EST, expressed sequence tags; n.d.; not determined.

seven isolates was identical to sFRP4, which was identified as a novel up-regulated gene during pregnancy. sFRP4 is a member of the secreted frizzled-related protein family, and previously reported to be expressed in mammary gland, ovary and prostate (Wolf et al. 1997).

Since up-regulation of sFRP4 during pregnancy is a novel finding, we focused on sFRP4 for further study. sFRP4 contains a cysteine-rich domain (CRD) that functions as a Wnt-binding domain in frizzled proteins (Wolf et al. 1997). While frizzled proteins have a seven-pass transmembrane domain (Bhanot et al. 1996), secreted frizzled-related proteins including sFRP4 lack this domain.

The size of sFRP4 cDNA was reported to be 1910 nucleotides containing a $1044 \mathrm{bp}$ open reading frame that encodes 348 amino acids (Wolf et al. 1997). The fragment size of our isolated fragment was $474 \mathrm{bp}$ and corresponded to the fragment of nucleotides 661-1134 of sFRP4 cRNA (Wolf et al. 1997) (Fig. 1).

\section{Expression of sFRP4 during pregnancy}

To determine the expression pattern of sFRP4 mRNA during pregnancy, Northern blot analysis was performed for non-pregnant uteri and pregnant uteri on days 6, 9, 12 and 15. As shown in Fig. $2 \mathrm{~A}$, variable amounts of $2.0 \mathrm{~kb}$ and $2.9 \mathrm{~kb} \mathrm{sFRP} 4$ mRNAs were detected in the pregnant uteri on days 9, 12 and 15. In contrast, sFRP4 mRNA was not detected in the pregnant uteri on day 6 and in non-pregnant uteri. The intensity of the hybridization bands was measured by a phosphor imager, and sFRP4 signals were normalized utilizing the GAPDH signals for each time point. The intensity of sFRP4 signal exhibited its peak on day 12 and declined gradually thereafter (Fig. 2B).

We further investigated the cell type-specific expression of sFRP4 in the pregnant uteri on day 12. In situ hybridization histochemistry revealed specific distributions of the sFRP4 transcripts, especially in the decidua and weakly in the myometrium (Fig. 3A). Control sections treated with sFRP4 sense probe showed no specific signals (Fig. 3B). In addition, the expression of ER $\alpha$ mRNA was investigated using an ER $\alpha$-specific antisense probe. Although ER $\alpha$ mRNA was detected in the serosa, myometrium and decidua, strong signals were observed especially in the

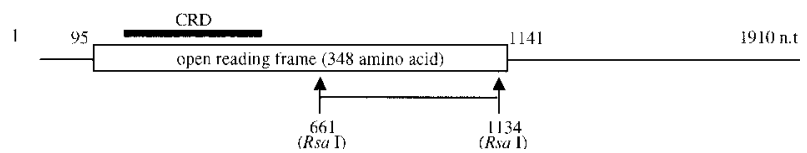

Figure 1 Isolated cDNA fragment of sFRP4. The size of the cDNA fragment was $474 \mathrm{bp}$ and corresponded to the fragment of nucleotides 661-1134 of sFRP4 (Wolf et al. 1997). Both ends of the fragment contain Rsal sites because the synthesized double-stranded cDNA was digested with this restriction enzyme. 


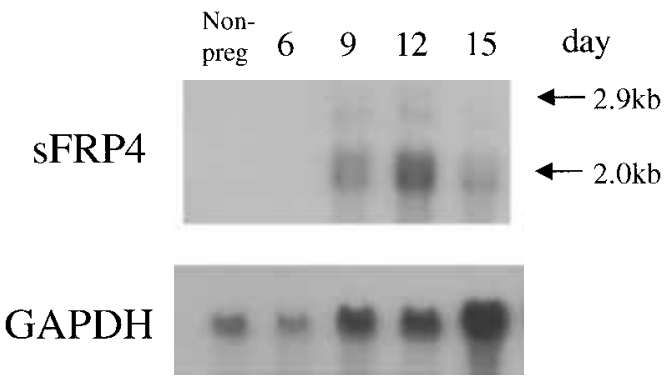

B

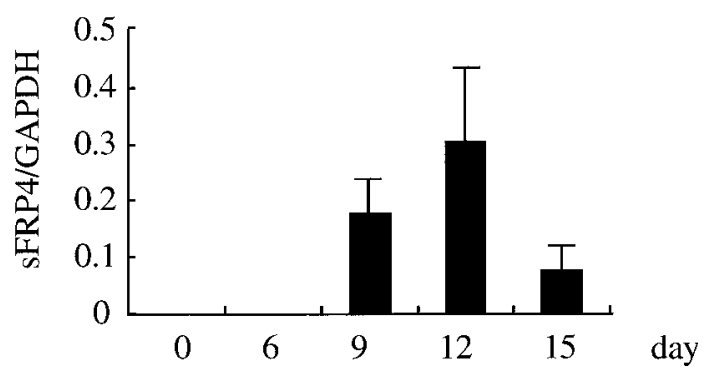

Figure 2 Expression of sFRP4 mRNA in rat uterus during pregnancy. (A) Northern blots containing total RNA $(20 \mu \mathrm{g})$ extracted from non-pregnant (Non-preg) uteri and pregnant uteri on days 6, 9, 12 and 15 were hybridized with the sFRP4 cDNA probe or the GAPDH probe as an internal control. Variable amounts of $2.0 \mathrm{~kb}$ and $2.9 \mathrm{~kb}$ sFRP4 transcripts were detected in pregnant uteri on days 9,12 and 15 . In contrast, sFRP4 mRNA was not detected in non-pregnant uteri and pregnant uteri on day 6. (B) Semiquantitative analysis of the ratio of sFRP4 transcripts levels against GAPDH transcripts levels in pregnant uteri on days 9,12 , and $15(n=3$ for each group). Values are means \pm S.D.

decidua (Fig. 3C) where the sFRP4 transcripts were also detected (Fig. 3A). Control sections treated with $\mathrm{ER} \alpha$ sense probe showed no specific signals (Fig. 3D). We further investigated whether expression of sFRP4 was involved in proliferation of deciduae using serial sections. As shown in Fig. 4A, a strong signal of sFRP4 was observed in the decidua. Distribution of PGNA-positive cells was overlapped in the decidua (Fig. 4C), suggesting that sFRP4 expression was observed in proliferating deciduae. There was no staining observed when the PCNA antibody was replaced by the mouse IgG (Fig. 4D).

\section{Expression of sFRP4 by estrogen treatment}

To investigate the possibility that sFRP4 is regulated by estrogen, the estrogen-treated ovariectomized rats were used as a model. Northern hybridization analysis revealed that the sFRP4 signal was detected in the uteri at $48 \mathrm{~h}$ after estrogen treatment. In contrast, sFRP4 mRNA was not detected in uteri at $0,2,6$ and $24 \mathrm{~h}$ after estrogen treatment (Fig. 5A). No signal was observed at 0, 2, 6, 24 and $48 \mathrm{~h}$ after oil treatment (Fig. 5B). In situ hybridization histochemistry showed that sFRP4 mRNA was expressed predominantly in the endometrial stroma and less abundantly in the myometrium, whereas it was not detected in either luminal or glandular epithelium (Fig. 6A). The expression of sFRP4 in the endometrial stroma was observed more clearly by higher magnification (Fig. 6B). PGNA-positive cells were detected in the endometrial stroma, luminal epithelium and glandular epithelium (Fig. 6C).

\section{Discussion}

In the present study, using SSH we identified seven independent transcripts that up-regulated in the pregnant rat uterus. Six out of seven clones were previously known genes that up-regulate during pregnancy. One differentially expressed clone out of seven was found to be sFRP4 and this is the first report that sFRP4 is up-regulated during pregnancy. Amino acid sequences of sFRP4 proteins are well conserved among species. Rat sFRP4 was originally isolated from rat apoptotic tissues such as ovarian corpus luteum around parturition, involuted mammary gland and ventral prostate (Wolf et al. 1997, Guo et al. 1998). A human homologue of sFRP4 was identified as an up-regulated gene in endometrial carcinoma compared with normal endometrium (Abu-Jawdeh et al. 1999). A mouse homologue of sFRP4 was expressed in the developing teeth, eye and salivary gland of the embryo (Leimeister et al. 1998).

sFRP4 has a CRD, which functions as a Wnt-binding domain (Wolf et al. 1997). The Wnt family appears to induce multiple biological functions including cell growth, differentiation and survival (McMahon \& Bradley 1990, Thomas \& Capecchi 1990, Danielian \& McMahon 1996). Wnt signal is transduced inside the cell by frizzled 

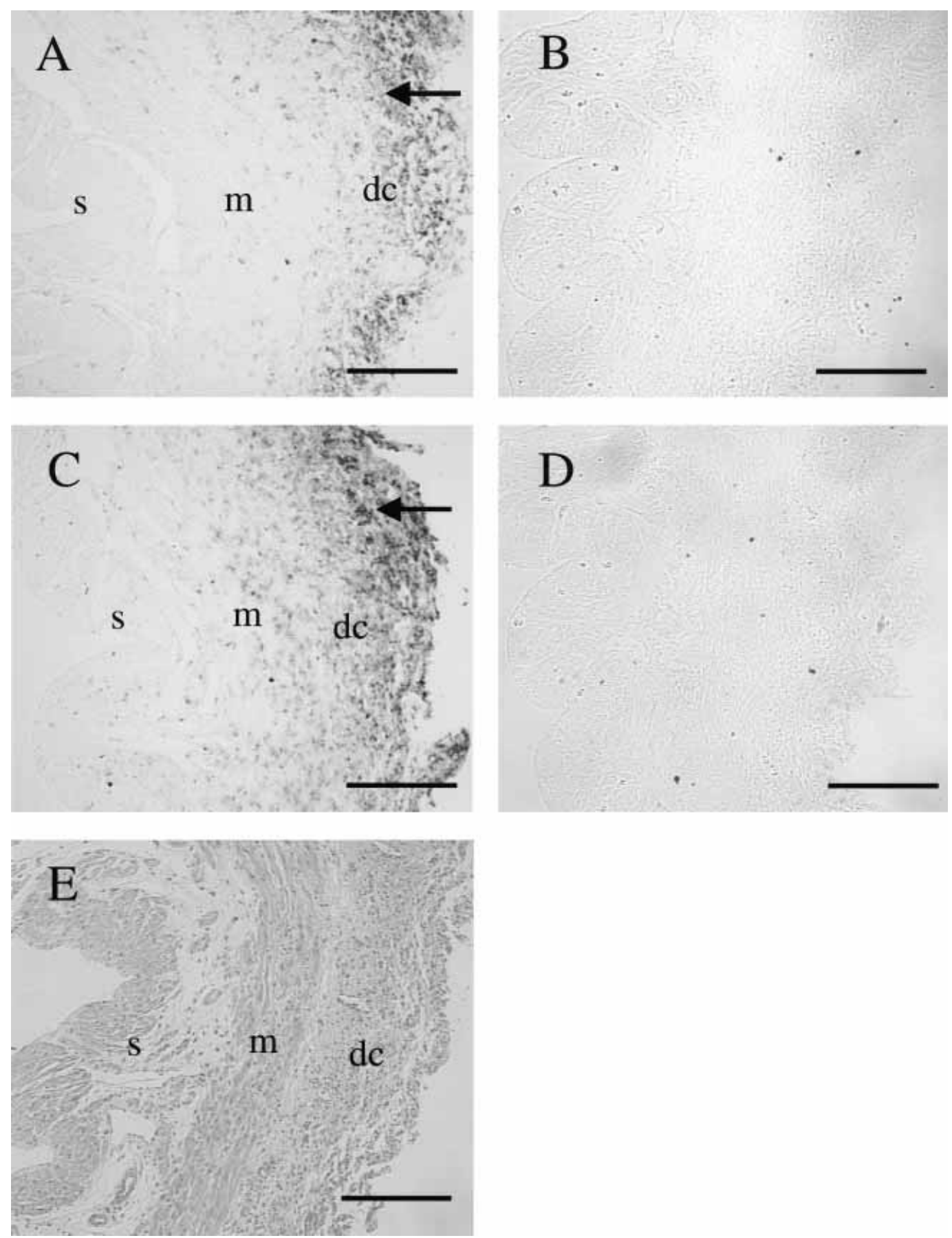

Figure 3 Distribution of sFRP4 mRNA and ER $\alpha$ mRNA in pregnant rat uteri on day 12. In situ hybridization histochemistry of sFRP4 $(A, B)$ and $E R \alpha(C, D)$ and hematoxylin and eosin staining (E) were performed using pregnant uteri on day 12. (A) SFRP4 mRNA was detected in the decidua (dc) as indicated by the arrow when SFRP4-specific antisense RNA probe was used. (B) No signal was detected by sFRP4 sense probe. (C) ER $\alpha$ mRNA was detected especially in the decidua (dc) as indicated by the arrow when the ER $\alpha$-specific antisense RNA probe was used. ER $\alpha$ mRNA was also observed in the myometrium $(\mathrm{m})$ and serosa (s). (D) No signal was detected by the $\mathrm{ER} \alpha$ sense probe. All experiments were performed three times. Bars $=200 \mu \mathrm{m}$. 

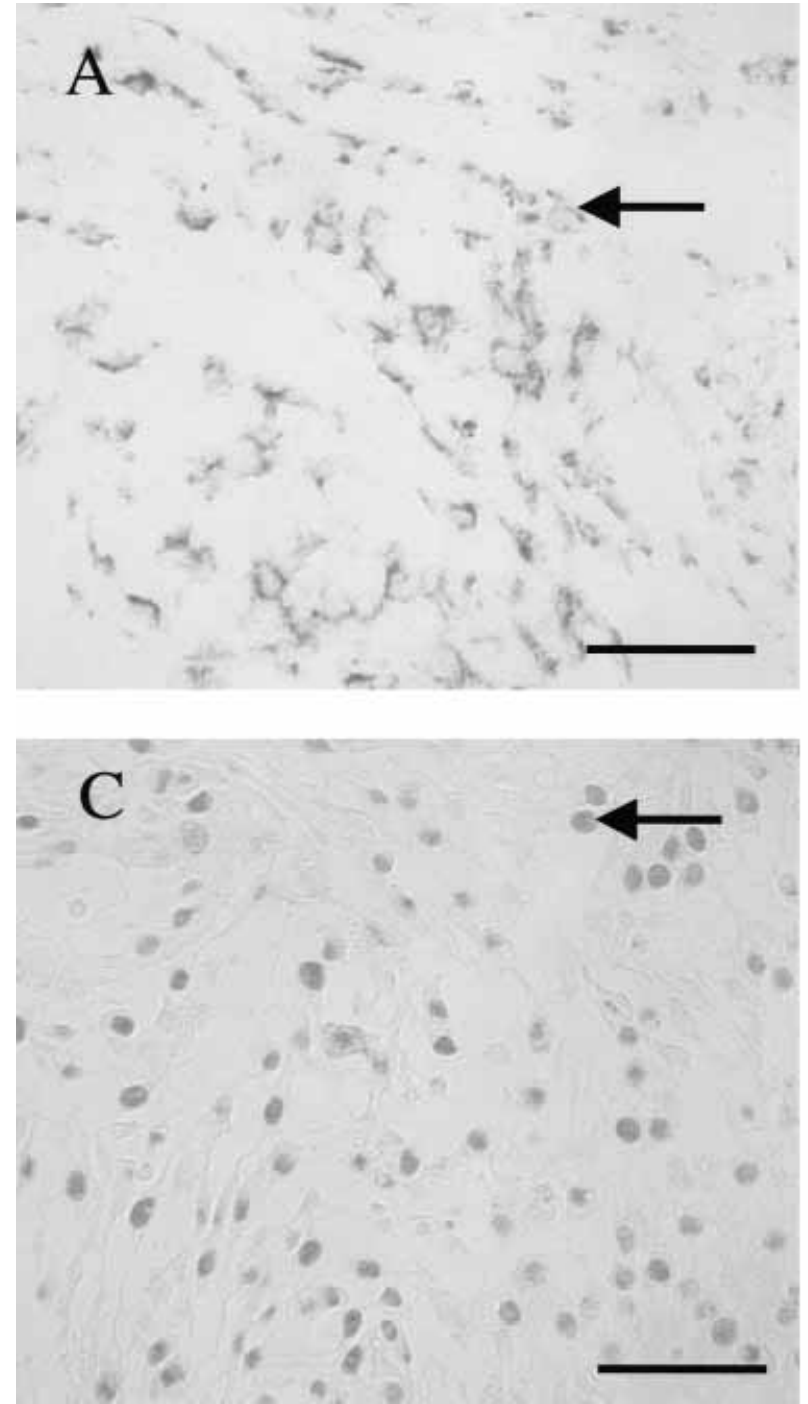

B

\section{$\mathrm{D}$}

Figure 4 Proliferating cell nuclear antigen (PCNA)-positive cells were overlapped in the deciduae where sFRP4 mRNA was detected. In situ hybridization histochemistry of SFRP4 (A, B) and immunostaining of PCNA (C, D) were performed using serial sections of pregnant uteri on day 12. (A) Strong signal of sFRP4 mRNA was observed in the decidua. One of the positive signals of sFRP4 is marked with an arrow. (B) No signal was detected by sFRP4 sense probe. (C) PCNA-positive cells were also detected in the decidua. One of the positive signals for PCNA is marked with an arrow. (D) No signal was detected when mouse IgG was utilized. All experiments were performed three times. Bars $=50 \mu \mathrm{m}$.

proteins, which contain a CRD and a seven-pass transmembrane domain (Bhanot et al. 1996). In contrast, secreted frizzled-related proteins, which possess a conserved CRD, lack the transmembrane domain. Although the biological activities of secreted frizzled proteins remain to be studied, they are assumed to function as modulators of the Wnt-frizzled signaling pathway. For example, it is reported that human frpHE antagonized the
Wnt-8-mediated dorsal axis duplication in the Xenopus embryo (Abu-Jawdeh et al. 1999), suggesting that sFRP4 antagonizes Wnt signaling. In the rodent uterus, it is known that some Wnt genes such as Wnt-4, $-5 a$ and $-7 a$ are expressed (Miller et al. 1998). Wnt-4 and $-5 a$ are expressed in the mouse uterine epithelium and stroma. Wnt-7a is expressed within the luminal epithelium. The expression levels of those Wnt genes in the uterus vary during the 


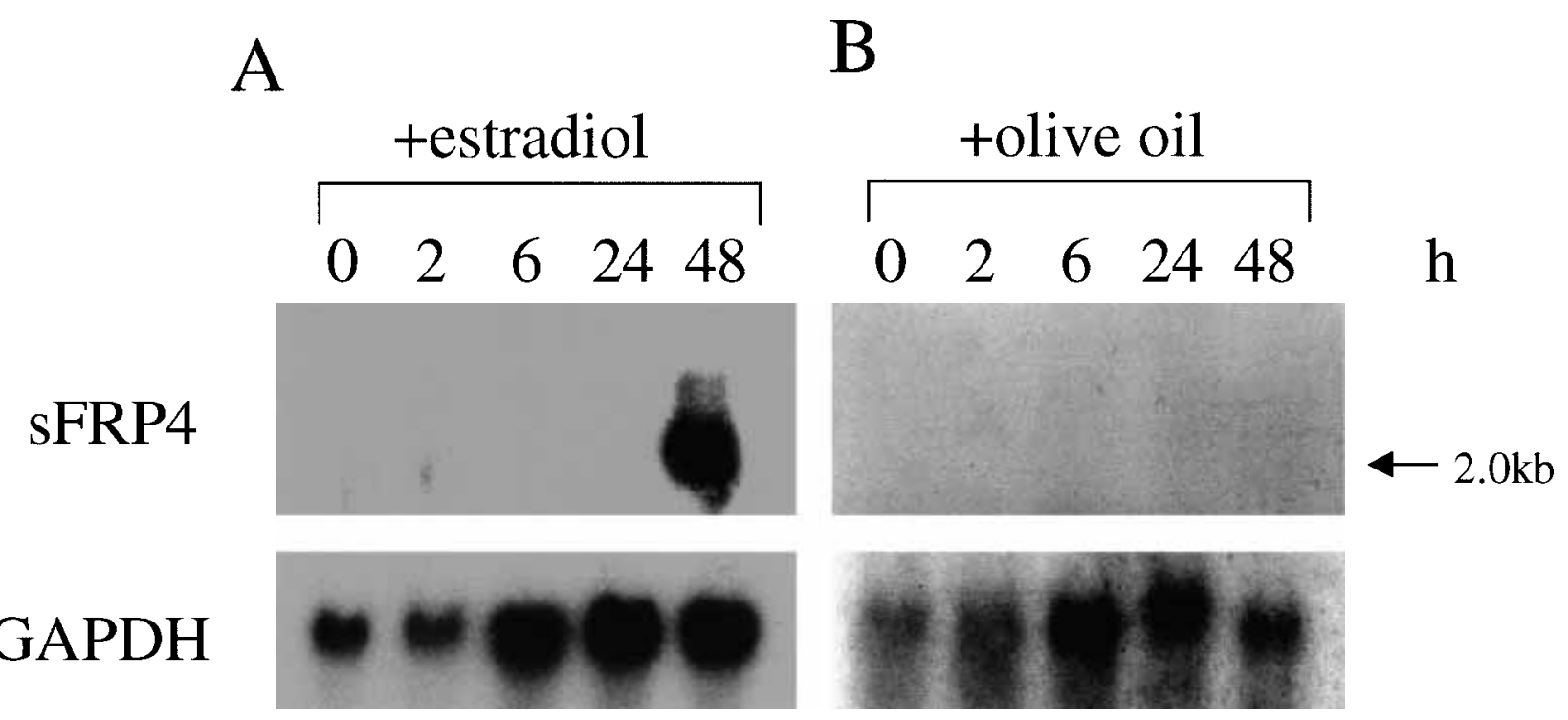

Figure 5 sFRP4 mRNA was regulated by estrogen in the uterus. Northern blots containing total RNA $(20 \mu \mathrm{g})$ extracted from the ovariectomized rat uteri at $0,2,6,24$ and $48 \mathrm{~h}$ after estradiol treatment $(10 \mu \mathrm{g} / \mathrm{kg})$ or olive oil treatment were hybridized with the sFRP4 cDNA probe or the GAPDH probe as an internal control. (A) sFRP4 mRNA was detected only in the uterus at $48 \mathrm{~h}$ after the treatment. (B) No signal was detected after olive oil injection. All experiments were performed three times.

estrous cycle (Miller et al. 1998), suggesting that those expressions may be regulated by estrogen and play key roles in adult uterine function including the morphological changes which occur in response to circulating hormone levels (Miller \& Sassoon 1998). It was also reported that the uteri of Wnt-7a-null mutant mice were smaller than that of wild type, absence of uterine glands and reduction in the mesenchymally derived stroma suggesting that $W n t-7 a$ is required in cytodifferentiation in the uterus (Parr \& McMahon 1998). During pregnancy, the expression of Wnt-4 observed in the stroma surrounding the embryo at the onset of implantation and then the expression increased in the decidua (Paria et al. 2001). From the structural aspects of sFRP4, it is tempting to speculate that sFRP4 modulates the Wnt signal pathway via binding to some Wnt genes such as Wnt $-4,-5 a$ and $-7 a$.

Northern blot analysis revealed that the expression of sFRP4 mRNA was highest in the pregnant uteri on day 12. In situ hybridization histochemistry demonstrated that sFRP4 mRNA expression was restricted to the decidual cells. Moreover, PCNApositive cells were mainly found in the decidual cells, where sFRP4 mRNA was detected. In the pregnant rat, endometrial stromal cells begin to proliferate and differentiate to form decidual tissue after implantation on day 6 (Abrahamsohn \& Zorn 1993), and proliferation continues until day 12 when decidualization completes (Ogle et al. 1998). Thus, it is possible that the marked increase of sFRP4 transcripts in the decidua on day 12 was accompanied by the late phase of decidual cell proliferation. Alternatively, it is known that internucleosomal DNA fragmentation in the decidua basalis begins in mid-pregnancy (Ogle et al. 1999). From day 14, the decidual tissue begins to regress to the end of pregnancy (Ogle et al. 1990, $\mathrm{Gu}$ et al. 1994). The controlled cell death of large numbers of decidual cells allows remodeling of the implantation chamber without disrupting the growth and development of the embryo or the integrity of the uterus (Welsh \& Enders 1985). Another study indicated that DNA breakdown was first detected at day 10 and that it increased time-dependently (Gu et al. 1994, Moulton 1994). Taken together, it is possible that sFRP4 might be involved in the initiation of decidual apoptosis by modulating some Wnt signals.

$\mathrm{ER} \alpha \mathrm{mRNA}$ was detected in the decidua as well as sFRP4 mRNA. It is known that the steroid hormones such as estrogen and progesterone modulate the structure and function of the uterus during pregnancy through their nuclear receptors 

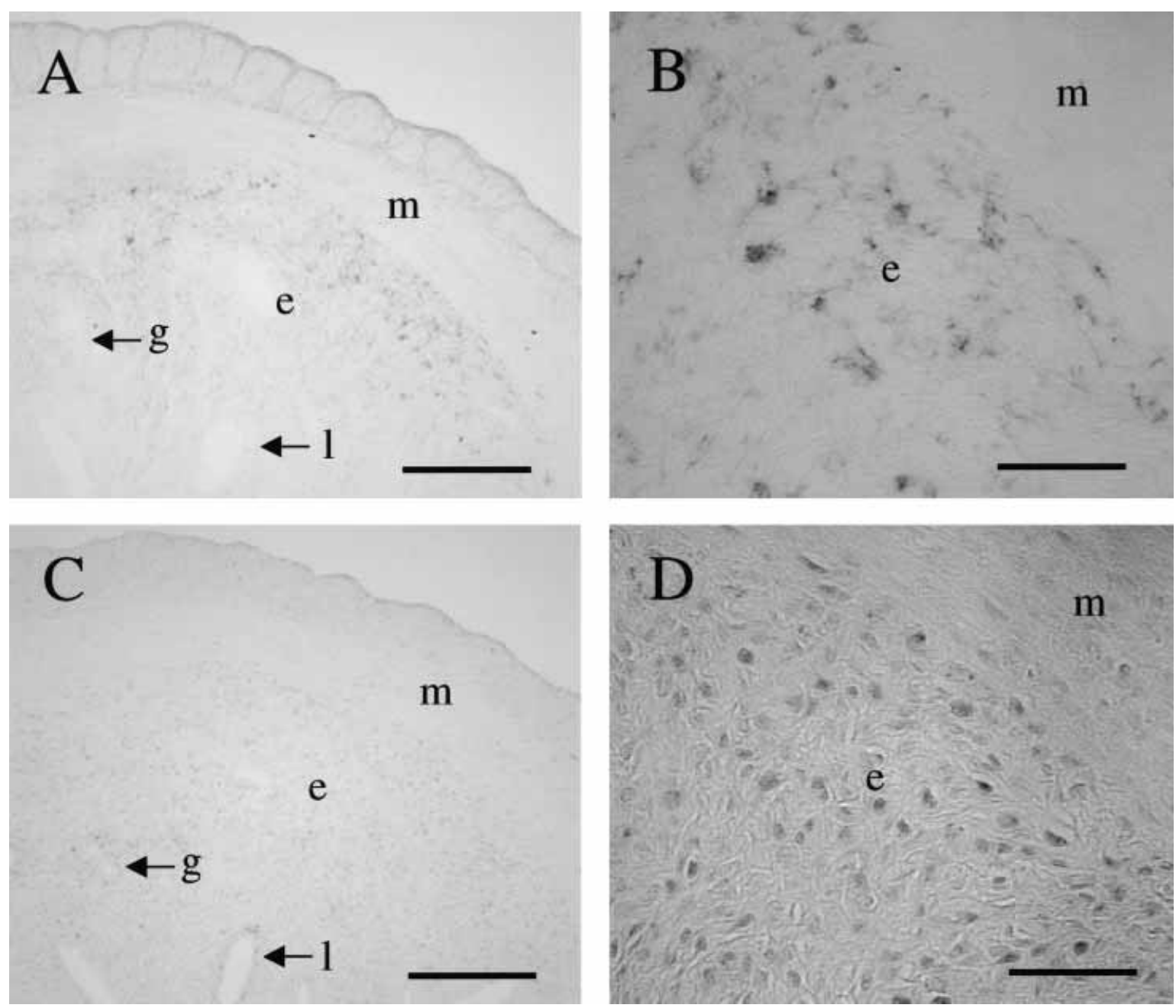

Figure 6 Distribution of sFRP4 mRNA and PCNA-positive cells in rat uteri at $48 \mathrm{~h}$ after estrogen treatment. In situ hybridization histochemistry of SFRP4 (A, B) and immunostaining of PCNA (C, D) were performed using ovariectomized rat uteri at $48 \mathrm{~h}$ after estrogen treatment. (A) sFRP4 mRNA was expressed abundantly in the endometrial stroma $(\mathrm{e})$ whereas there was little in the myometrium $(\mathrm{m})$ when hybridized with sFRP4-specific antisense RNA probe. No sFRP4 mRNA expression was detected in either the luminal epithelium (I) or glandular epithelium (g). (B) Higher magnification of (A). (C) PCNA-positive cells were detected in the stroma, luminal epithelium and glandular epithelium. (D) Higher magnification of (C). All experiments were performed three times. Bars represent (A, C) $200 \mu \mathrm{m}$ and (B, D) $50 \mu \mathrm{m}$.

(Pepe \& Albrecht 1995). Thus, we speculate the regulation of ${ }_{\mathrm{s}} \mathrm{FR} 4$ expression by estrogen in the uterus. To investigate this possibility, we used ovariectomized rats treated with estrogen. sFRP4 mRNA expression was detected $48 \mathrm{~h}$ after estrogen treatment. Unlike during pregnancy, the $2 \cdot 0 \mathrm{~kb}$ sFRP4 transcript was observed whereas the $2.9 \mathrm{~kb}$ transcript was not. It is possible that several splice variants of sFRP4 may exist and only the $2 \cdot 0 \mathrm{~kb}$ transcript can be especially up-regulated by estrogen. Alternatively, other transcripts were not detected in our Northern analysis because the expression levels were lower. In general, direct estrogen-responsive genes are up-regulated within several hours of estrogen treatment. For example, the level of progesterone receptor mRNA was elevated within $2 \mathrm{~h}$ after a single injection of $17 \beta$ estradiol (Shughrue et al. 1997). It was rather late that sFRP4 mRNA was detected in the uterus, at $48 \mathrm{~h}$ after estrogen injection, suggesting that up-regulation of sFRP4 may be an indirect effect of estrogen. 
The expression of sFRP4 mRNA was observed in the proliferating endometrial stroma. It was reported that the maximal number of PGNApositive cells was found after $36 \mathrm{~h}$ in the epithelium and stroma (Gunin 1997). Thus, the expression of sFRP4 mRNA might be accompanied by the late phase of proliferation after estrogen treatment.

In summary, we have identified sFRP4 as an up-regulated gene in the uterus during pregnancy. Our present data suggest that the expression of sFRP4 mRNA was accompanied by a late phase of proliferation in the decidual cells. It is possible that sFRP4 modulates signals of Wnt genes in the pregnant uterus.

\section{Acknowledgements}

We thank Ms M Kobayashi and Ms S Inada for expert technical assistance. This work was supported in part by research grants from the Ministry of Education, Science and Culture of Japan, and research grants from the Comprehensive Research on Aging and Health, the Ministry of Health and Welfare of Japan.

\section{References}

Abrahamsohn PA \& Zorn TM 1993 Implantation and decidualization in rodents. Fournal of Experimental Zoology $\mathbf{2 6 6}$ 603-628.

Abu-Jawdeh G, Comella N, Tomita Y, Brown LF, Tognazzi K, Sokol SY \& Kocher O 1999 Differential expression of frpHE: a novel human stromal protein of the secreted frizzled gene family, during the endometrial cycle and malignancy. Laboratory Investigation 79 439-447.

Bhanot P, Brink M, Samos CH, Hsieh JC, Wang Y, Macke JP, Andrew D, Nathans J \& Nusse R 1996 A new member of the frizzled family from Drosophila functions as a Wingless receptor. Nature 382 225-230.

Charnock JD, Sharkey AM, Fenwick P \& Smith SK 1994 Leukaemia inhibitory factor mRNA concentration peaks in human endometrium at the time of implantation and the blastocyst contains mRNA for the receptor at this time. Fournal of Reproduction and Fertility $101421-426$.

Chen H, Chen CL \& Chou JY 1994 Characterization of two promoters of a rat pregnancy-specific glycoprotein gene. Biochemistry 33 9615-9626.

Chibbar R, Wong S, Miller FD \& Mitchell BF 1995 Estrogen stimulates oxytocin gene expression in human chorio-decidua. Journal of Clinical Endocrinology and Metabolism 80 567-572.

Danielian PS \& McMahon AP 1996 Engrailed-1 as a target of the Wnt-1 signalling pathway in vertebrate midbrain development. Nature 383 332-334.

Diatchenko L, Lau YF, Campbell AP, Chenchik A, Moqadam F, Huang B, Lukyanov S, Lukyanov K, Gurskaya N, Sverdlov ED \& Siebert PD 1996 Suppression subtractive hybridization: a method for generating differentially regulated or tissue-specific cDNA probes and libraries. PNAS 93 6025-6030.

Diatchenko L, Lukyanov S, Lau YF \& Siebert PD 1999 Suppression subtractive hybridization: a versatile method for identifying differentially expressed genes. Methods in Enzymology 303 349-380

Dowell RT \& Kauer CD 1997 Maternal hemodynamics and uteroplacental blood flow throughout gestation in conscious rats. Methods and Findings in Experimental and Clinical Pharmacology 19 613-625.

Faria TN, Deb S, Kwok SC, Talamantes F \& Soares MJ 1990 Ontogeny of placental lactogen-I and placental lactogen-II expression in the developing rat placenta. Developmental Biology 141 279-291.

Fletcher S, Thomas T, Schreiber G, Heinrich PG \& Yeoh GC 1988 The development of rat $\alpha 2$-macroglobulin. Studies in vivo and in cultured fetal rat hepatocytes. European Fournal of Biochemistry 171 703-709.

Fu X, Ulmsten U \& Backstrom T 1994 Interaction of sex steroids and oxytocin on term human myometrial contractile activity in vitro. Obstetrics and Gynecology $84272-277$.

Gu Y, Jow GM, Moulton BC, Lee C, Sensibar JA, Park-Sarge OK, Chen TJ \& Gibori G 1994 Apoptosis in decidual tissue regression and reorganization. Endocrinology 135 1272-1279.

Gunin AG 1997 Effect of heparin on oestradiol-induced cell growth and proliferation in the uterus of ovariectomized rats. Fournal of Endocrinology 154 441-448.

Guo K, Wolf V, Dharmarajan AM, Feng Z, Bielke W, Saurer S \& Friis R 1998 Apoptosis-associated gene expression in the corpus luteum of the rat. Biology of Reproduction 58 739-746.

Hansen PJ 1998 Regulation of uterine immune function by progesterone - lessons from the sheep. Fournal of Reproductive Immunology 40 63-79.

Hatthachote P \& Gillespie JI 1999 Complex interactions between sex steroids and cytokines in the human pregnant myometrium: evidence for an autocrine signaling system at term. Endocrinology $1402533-2540$.

Ishikawa K, Fujigasaki H, Saegusa H, Ohwada K, Fujita T, Iwamoto H, Komatsuzaki Y, Toru S, Toriyama H, Watanabe M, Ohkoshi N, Shoji S, Kanazawa I, Tanabe T \& Mizusawa H 1999 Abundant expression and cytoplasmic aggregations of $\alpha 1 \mathrm{~A}$ voltage-dependent calcium channel protein associated with neurodegeneration in spinocerebellar ataxia type 6. Human Molecular Genetics 8 1185-1193.

Kelman Z \& Hurwitz J 1998 Protein-PGNA interactions: a DNAscanning mechanism? Trends in Biochemical Science $23236-238$.

Koike S, Sakai M \& Muramatsu M 1987 Molecular cloning and characterization of rat estrogen receptor cDNA. Nucleic Acids Research 15 2499-2513.

Leimeister C, Bach A \& Gessler M 1998 Developmental expression patterns of mouse sFRP genes encoding members of the secreted frizzled related protein family. Mechanisms of Development $7529-42$.

Lim KJ, Odukoya OA, Ajjan RA, Li TC, Weetman AP \& Cooke ID 1998 Profile of cytokine mRNA expression in peri-implantation human endometrium. Molecular Human Reproduction 4 77-81.

Lingueglia E, Renard S, Voilley N, Waldmann R, Chassande O, Lazdunski M \& Barbry P 1993 Molecular cloning and functional expression of different molecular forms of rat amiloride-binding proteins. European Fournal of Biochemistry 216 679-687.

Macphee DJ \& Lye SJ 2000 Focal adhesion signaling in the rat myometrium is abruptly terminated with the onset of labor. Endocrinology $141274-283$.

McMahon AP \& Bradley A 1990 The Wnt-1 (int-1) proto-oncogene is required for development of a large region of the mouse brain. Cell 62 1073-1085.

Miller C \& Sassoon DA 1998 Wnt-7a maintains appropriate uterine patterning during the development of the mouse female reproductive tract. Development 125 3201-3211. 
Miller C, Pavlova A \& Sassoon DA 1998 Differential expression patterns of Wnt genes in the murine female reproductive tract during development and the estrous cycle. Mechanisms of Development 76 91-99.

Moulton BC 1994 Transforming growth factor-beta stimulates endometrial stromal apoptosis in vitro. Endocrinology 134 $1055-1060$

Ogawa S, Inoue S, Watanabe T, Orimo A, Hosoi T, Ouchi Y \& Muramatsu M 1998 Molecular cloning and characterization of human estrogen receptor $\beta \mathrm{cx}$ : a potential inhibitor of estrogen action in human. Nucleic Acids Research 26 3505-3512.

Ogle TF, Mills TM \& Costoff A 1990 Progesterone maintenance of the placental progesterone receptor and placental growth in ovariectomized rats. Biology of Reproduction 43 276-284.

Ogle TF, George P \& Dai D 1998 Progesterone and estrogen regulation of rat decidual cell expression of proliferating cell nuclear antigen. Biology of Reproduction $59444-450$.

Ogle TF, Dai D \& George P 1999 Progesterone-regulated determinants of stromal cell survival and death in uterine decidua are linked to protein kinase C activity. Steroids 64 628-633.

Orimo A, Inoue S, Ikeda K, Noji S \& Muramatsu M 1995 Molecular cloning, structure, and expression of mouse estrogenresponsive finger protein Efp. Co-localization with estrogen receptor mRNA in target organs. Fournal of Biological Chemistry 270 24406-24413.

Paria BC, Ma W, Tan J, Raja S, Das SK, Dey SK \& Hogan BLM 2001 Cellular and molecular responses of the uterus to embryo implantation can be elicited by locally applied growth factors. PNAS 98 1047-1052.

Parr BA \& McMahon AP 1998 Sexually dimorphic development of the mammalian reproductive tract requires Wnt-7a. Nature 395 707-710.

Pepe GJ \& Albrecht ED 1995 Actions of placental and fetal adrenal steroid hormones in primate pregnancy. Endocrine Reviewes 16 608-648.

Saito S, Ibaraki T, Enomoto M, Ichijo M \& Motoyoshi K 1994 Macrophage colony-stimulating factor induces the growth and differentiation of normal pregnancy human cytotrophoblast cells and hydatidiform moles but does not induce the growth and differentiation of choriocarcinoma cells. Fapanese Fournal of Cancer Research 85 245-252.

Shughrue PJ, Lane MV \& Merchenthaler I 1997 Regulation of progesterone receptor messenger ribonucleic acid in the rat medial preoptic nucleus by estrogenic and antiestrogenic compounds: an in situ hybridization study. Endocrinology 138 5476-5484.

Stewart EA, Floor AE, Jain P \& Nowak RA 1995 Increased expression of messenger RNA for collagen type I, collagen type III, and fibronectin in myometrium of pregnancy. Obstetrics and Gynecology 86 417-422.

Takahashi K, Akasaka M, Yamamoto Y, Kobayashi C, Mizoguchi J \& Koyama J 1990 Primary structure of human plasma glutathione peroxidase deduced from cDNA sequences. Fournal of Biochemistry 108 145-148.

Thomas KR \& Capecchi MR 1990 Targeted disruption of the murine int- 1 proto-oncogene resulting in severe abnormalities in midbrain and cerebellar development. Nature 346 847-850.

Thomas T 1993 Distribution of $\alpha-2$ macroglobulin and alpha 1 -acid glycoprotein mRNA shows regional specialization in rat decidua. Placenta 14 417-428.

Thordarson G, Southard JN \& Talamantes F 1991 Purification and characterization of mouse decidual calcyclin: a novel stimulator of mouse placental lactogen-II secretion. Endocrinology 129 $1257-1265$.

Tsurimoto T 1998 PCNA, a multifunctional ring on DNA. Biochimica et Biophysica Acta 1443 23-39.

Vogiagis D \& Salamonsen LA 1999 Review: the role of leukaemia inhibitory factor in the establishment of pregnancy. Fournal of Endocrinology 160 181-190.

Waterhouse P, Parhar RS, Guo X, Lala PK \& Denhardt DT 1992 Regulated temporal and spatial expression of the calciumbinding proteins calcyclin and OPN (osteopontin) in mouse tissues during pregnancy. Molecular Reproduction and Development 32 315-323.

Welsh AO \& Enders AC 1985 Light and electron microscopic examination of the mature decidual cells of the rat with emphasis on the antimesometrial decidua and its degeneration. American Fournal of Anatomy 172 1-29.

Wolf V, Ke G, Dharmarajan AM, Bielke W, Artuso L, Saurer S \& Friis R 1997 DDC-4, an apoptosis-associated gene, is a secreted frizzled relative. FEBS Letters 417 385-389.

de Ziegler D, Fanchin R, de Moustier B \& Bulletti C 1998 The hormonal control of endometrial receptivity: estrogen (E2) and progesterone. Fournal of Reproductive Immunology 39 149-166.

Received 25 February 2002 Accepted 25 March 2002 